
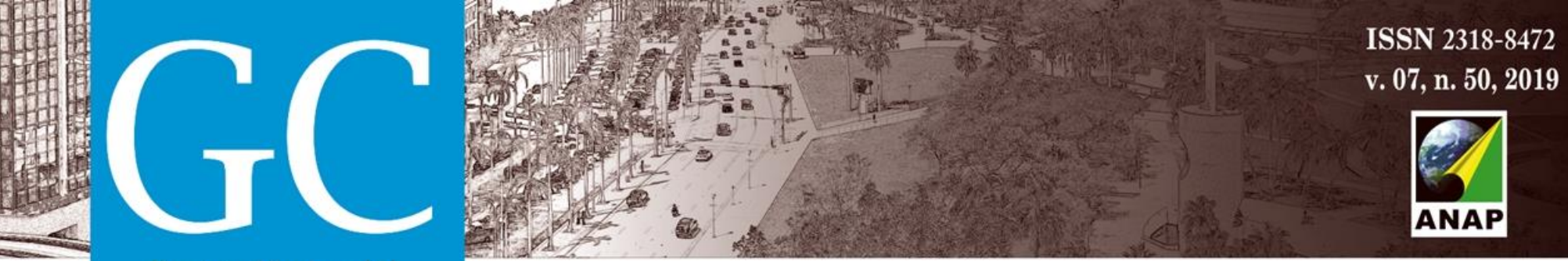

v. 07 , n. 50, 2019

Revista Nacional de

Gerenciamento de Cidades

\title{
O Rio Tietê e as cidades de Barra Bonita e Igaraçu do Tietê
}

Tietê River and the cities of Barra Bonita and Igaraçu do Tietê

Río Tietê en las ciudades de Barra Bonita e Igaraçu do Tietê

Gabriela Rosa

Mestranda, UNESP, Brasil

gabriela.rosa@unesp.br

Norma Regina Truppel Constantino

Professora Doutora, UNESP, Brasil

mrosario@gmai.com 


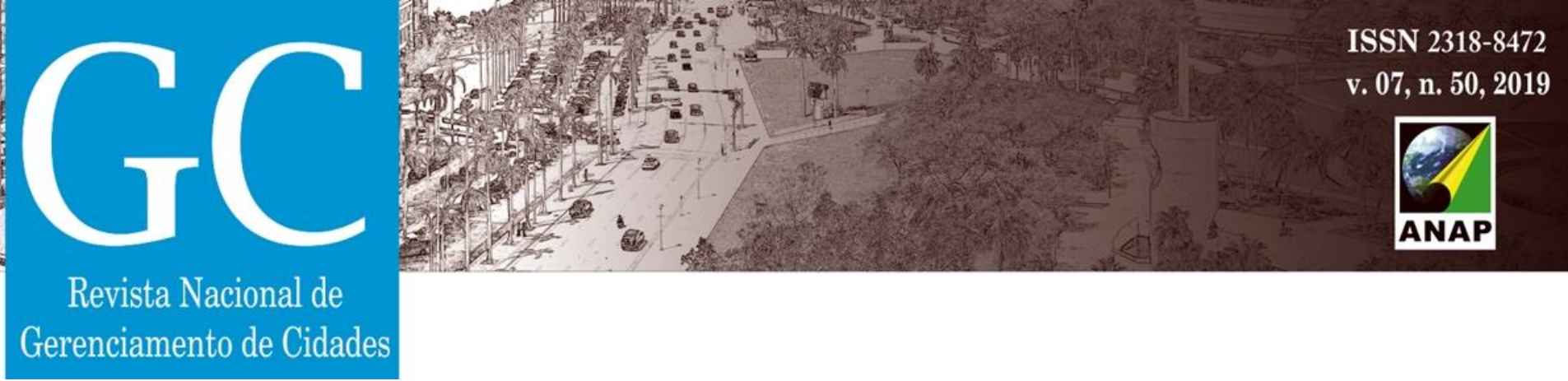

\section{INTRODUÇÃO}

A compreensão da relação entre os rios e a paisagem urbana é muito importante, pois a história da interação rio-cidade sempre mostrou que as cidades eram frequentemente construídas em torno dos rios por conta do acesso à água e para o comércio e agricultura, uma vez que a topografia ripária é favorável (LENER; HOLT, 2012). As cidades, antigas ou novas, são marcadas pelos cursos hídricos e pelas formas como eles foram utilizados. Os rios, córregos ou lagos e seus aspectos naturais como as cheias, afetam a sociedade que ali vive e trazem uma dinâmica paisagística que é influenciada pela forma como o homem se relaciona com o ambiente em que está inserido. As águas, devido ao valor histórico que lhes foi atribuído na formação territorial e urbana e a maneira como foram utilizadas e manipuladas, possuem diferentes valores que contribuem de forma positiva ou negativa para a identidade local.

\footnotetext{
A água nas cidades é também frescura, o contraponto a condições climáticas mais extremas, podendo ser assegurada pela presença de elementos e plano de água, ou através da vegetação, que a lança para o ar sob a forma de vapor, através da transpiração, contribuindo para um microclima mais ameno. A água nas cidades pode também ser o elemento estético e decorativo que, pelo movimento, pela reflexão, pelo som, pela luz e pela imagem, introduz variedade, diversidade e beleza, contribuindo para a identidade e carácter do espaço urbano. (SARAIVA, 2006, p.5)
}

Contudo, para o entendimento de como os rios estão situados no contexto urbano, é antes necessário compreender o conceito de paisagem. A paisagem é uma palavra que tem múltiplos significados. Para Meinig (1979), ela pode se apresentar como natureza, habitat, artefato, sistema, problema, riqueza, ideologia, história, lugar e estética. Besse (2014) sintetiza essas categorias em cinco formas principais de se conceber a paisagem: como representação cultural e social; como território produzido pelas sociedades ao longo da história; como complexo sistêmico; como espaço de uma experiência fenomenológica e, também como projeto. Porém, é possível perceber a paisagem como o conjunto de tudo isso, conciliando tanto os aspectos físicos, sociais e históricos, quanto àqueles ideológicos e psicológicos. Meinig (1979) sintetiza essa ideia, dizendo que qualquer paisagem é composta não só por aqui que nossos olhos vêem, mas também a partir da nossa própria percepção individual".

As paisagens são parte da nossa vida cotidiana e estão presentes tanto no plano individual (nosso ser), quanto no plano coletivo (nossa vida) (BESSE, 2013). Não se trata de apenas uma vista, mas elas compreendem um mundo vivido, fabricado ou habitado por sociedades humanas em constante mudança (BESSE, 2014). A construção da paisagem é um processo histórico de representação das relações sociais, nas quais práticas e ideologias tornam-se realidades materiais pela transformação de seu significado na criação de lugares (LEITE, 1996). Nesse sentido, os lugares são fenômenos qualitativos, que ultrapassam o conceito de localização, pois trazem consigo simbolismos, caráter e identidade de um determinado local (NORBERG-SCHULZ, 2006). 


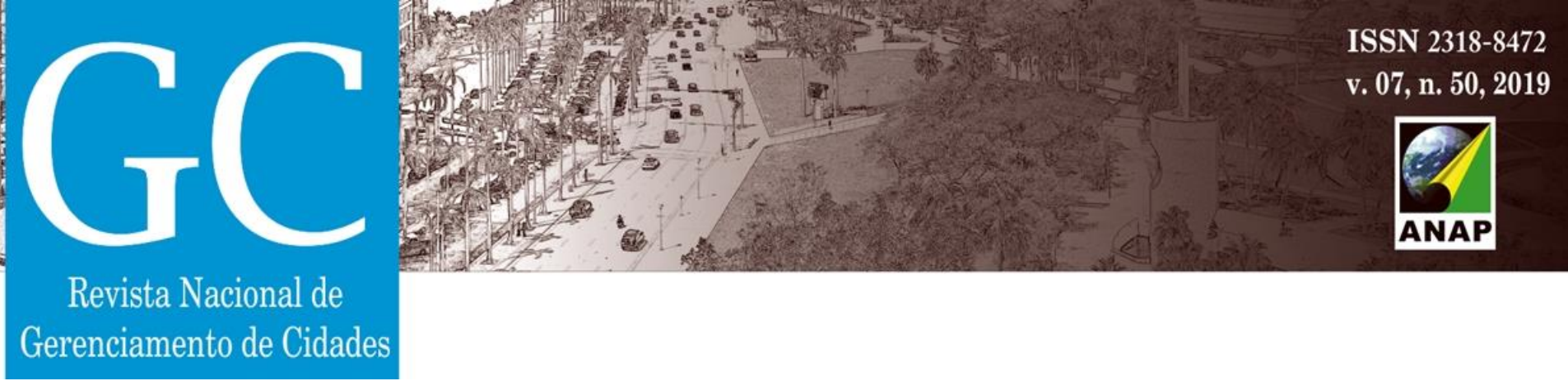

Assim sendo, a interação rio-cidade é uma interessante relação a ser analisada do ponto de vista de paisagem, pois agrega meios naturais, culturais e históricos. Compreender esta relação, porém, não é apenas observar seus aspectos físicos, mas sim compreender como os rios se inserem no contexto de lugar e como essa noção foi sendo alterada ao longo da história. Desse modo, será possível perceber de que modo os rios estão inseridos na paisagem, uma vez que, segundo Serrão (2014, p. 26) "paisagem não é a natureza (em si) nem o humano (para si), mas o ponto de encontro de homem e natureza".

\subsection{A relação Cidade e Rio}

O desenvolvimento da forma de organização espacial e consumo alterou a relação do homem com a água. A partir da revolução industrial iniciada na Inglaterra, e repercutida para o mundo no final do século XIX e durante século XX, houve um adensamento populacional nas cidades, criando sociedades essencialmente urbanas que trouxeram consigo problemas habitacionais, sociais e ambientais. O processo de urbanização e o desenvolvimento tecnológico exploraram os recursos naturais na maioria dos países do mundo, transformando-os em mercadorias. "Nessa perspectiva, as mesmas águas que atraíram o surgimento das cidades, são as mesmas que amedrontam as suas populações." (GRATÃO, 2006, p. 6). A exploração dos recursos hídricos foi intensificada possibilitando energia e transporte, além de, infelizmente, depósito de lixo e esgoto, alterando sua paisagem. São vistos muitas vezes como empecilhos para o desenvolvimento dentro das aglomerações urbanas.

O homem submete e explora o próprio homem transformando a natureza em recursos e, a sua própria natureza. A relação de produção faz os homens donos da Terra.

\footnotetext{
A natureza passa a ser considerada com um objeto, uma mercadoria; uma fonte de riqueza (GRATÃO, 2002, p. 11). Nesse processo, são cortados os laços naturais e culturais com a Terra. Mais uma vez, é esse o mesmo processo que determina as formas de relacionamento e de vida nas cidades. (GRATÃO, 2006, p. 4)
}

A degradação dos recursos naturais, inclusive dos recursos hídricos, gera consequências ao meio ambiente. Tais consequências começaram a ser debatidas mundialmente na segunda metade do século XX em busca de soluções para geração de uma sociedade sustentável. A questão é: como tornar-se uma sociedade sustentável que valoriza os recursos naturais em um momento em que o consumo desses recursos é essencial para manutenção da economia mundial vigente? Segundo Saraiva (2006) os caminhos para o desenvolvimento sustentável abrangem diversas áreas e esferas de ação. Um manejo adequado das águas e do meio ambiente requer a mudança de comportamentos, processos e procedimentos realizados atualmente em prol de ações que visem um menor consumo e maior conservação dos recursos naturais.

$\mathrm{Na}$ escala da cidade, a questão da sustentabilidade voltada aos cursos d'água abrange soluções mais específicas tentando resgatar a relação entre homem e água. Segundo Costa e Monteiro (2002), é necessária a criação de meios que gerem novamente a visualização e valorização dos 


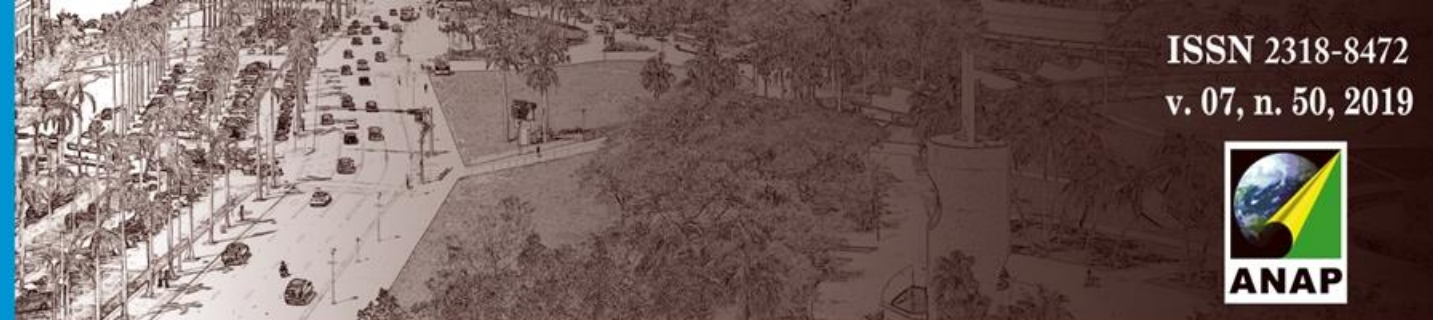

Revista Nacional de

Gerenciamento de Cidades

recursos naturais e da água por parte da população através da alteração da paisagem urbana atual. A "[...] visibilidade é uma importante atitude projetual na direção de um comportamento ambiental responsável". (COSTA; MONTEIRO, 2002, p. 291). A paisagem urbana precisa ser pensada e reprojetada para direcionar o olhar do cidadão para os rios e córregos.

As cidades brasileiras se desenvolveram aos moldes europeus pós-liberais de urbanização que valorizava o desenvolvimento a qualquer custo (HERZOG, 2013). A partir de 1930, começou o incentivo à industrialização do país, com o foco o desenvolvimento da região Sudeste e principalmente a cidade de São Paulo (SENE; MOREIRA, 2009). Porém, o desenvolvimento acelerado e sem planejamento fez com que os rios se tornassem esgotos a céu aberto. Por esse motivo, o Brasil também adotou o discurso higienista (originária no século XVIII na Europa), que buscava melhorar a salubridade das cidades. Os higienistas, baseados nas teorias que relacionavam a doença com o meio ambiente, começaram a sugerir normas de organização das cidades, que, dentre muitas, propunham a canalização de rios e aterramento de áreas alagáveis, transferindo a poluição para locais não visíveis aos olhos humanos (COSTA, 2006). $O$ alto grau de impermeabilização dos solos, bem como a elaboração de projetos de drenagem inadequados presentes no histórico de urbanização brasileira, tem acarretado inundações frequentes em época de alta pluviosidade (SNSB, 2005).

Essa forma de desenvolvimento gerou algumas consequências socioambientais negativas. A dependência do trânsito motorizado e a presença de construções mineralizadas geraram uma cidade altamente poluente e com grande especulação imobiliária, o que fez com que a população com menor renda fosse obrigada a viver às margens das cidades ou em locais legalmente proibidos à construção, como beira de rios e lagos, que, em muitos casos, deveriam ser zonas de proteção ambiental (HERZOG, 2013). Contudo, a ocupação das áreas dos rios, não foi apenas fruto da ocupação desordenada, mas também causada pela ação deliberada de agenciamento das técnicas disponíveis para a restrição das áreas dos rios, visando disponibilizar áreas para urbanização (ANELLI, 2015).

O crescimento desordenado e a falta de cumprimento dos planos diretores tornaram os rios, muitas vezes, elementos indesejáveis no contexto urbano e grandes depósitos de esgoto. Segundo o Instituto Trata Brasil (2016), cerca de 60\% do esgoto do país não recebe tratamento e, considerando-se as regiões do Brasil, as regiões Sudeste e Sul contam com apenas 43,9\% do esgoto tratado. Esse despejo compromete a qualidade das águas, principal fator causador de mudanças nas características dos ecossistemas aquáticos inseridos no contexto urbano (CAMARGO et al., 1995; KÖNIG et al., 2008). Sem o devido planejamento urbano, a intervenção humana altera o curso ou as características de um rio, levando-os muitas vezes à degradação (XU et al., 2012).

A partir do final dos anos 90, aspectos ecológicos dentro das cidades começaram a ser intensivamente investigados, resultado da percepção de que as cidades são espaços socioecológicos (SUKOPP, 1998). Segundo Maddox et al. (2017) a natureza é um atributo de cada 


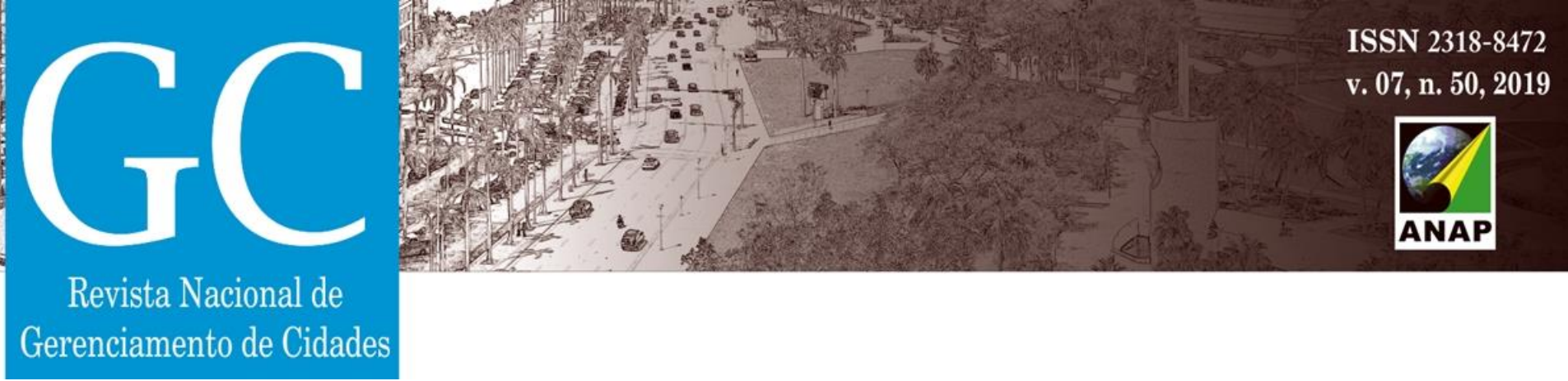

\section{RESULTADO}

\subsection{Rio Tietê e a dinâmica da paisagem}

No Brasil, os rios foram encarados como vias de penetração no interior do continente e se tornaram as bases de fixação dos povoamentos e limites políticos brasileiros (CÔRREA, 2008). Muitas das principais cidades brasileiras foram fundadas próximas a corpos d'água, principalmente devido as necessidades materiais vitais: a água para beber e a coleta de alimentos ofertados pelas zonas ripárias (MELLO, 2008). Considerando apenas o estado de São Paulo, foi o rio Tietê quem teve o papel central na história da ocupação e colonização do interior paulista, uma vez que este atravessa o estado de lesta a oeste (CÔRREA, 2008).

\footnotetext{
O Tietê, nessa conquista territorial, ligou o litoral ao sertão, facilitando o alargamento da capitania por terras litigiosas, além dos marcos chantados pelas comissões de limites luso-castelhanas. Por ele subiam as arcas de pregaria atestadas de barras louras, parte leonina da finta e da quintação, a fim de que o ouro brasileiro fosse, via Lisboa, encher os erários de Londres e Roma. Por ele viajaram capitães-mores, ouvidores-gerais e corregedores, cartorários e algazis[...] Por ele rondavam os canoões fatídicos, rumo dos presídios paludosos do Príncipe da Beira e do Iguatemi, cemitérios de milicianos e de povoadores obrigados a abandonar sítios e roças, sob pena de terem pais e filhos atirados ao aljube, em purga da deserção... Pelas águas barrentas do Tietê circulou a vida inteira da capitania, na centúria de setecentos... (NÓBREGA, 1978, p. 30)
}

Há uma relação intrínseca entre o rio Tietê e a formação e consolidação das cidades do Estado de São Paulo. Desde a formação da cidade de São Paulo, acima da Serra do Mar, e o posterior avanço em direção ao Planalto Central na exploração do Oeste, o Tietê e seus afluentes estiveram presentes e foram essenciais para o direcionamento, locomoção, abastecimento e desenvolvimento do estado. Aos poucos, a opção dos paulistas pelas monoculturas, indústrias, exploração, produção de energia e urbanização não planejada foi alterando sua paisagem, suas águas, seu desenho, suas margens e sua mata ciliar, sem avaliar as consequências desses atos, rompendo, ao longo dos anos, sua relação com os cursos d'água.

A exploração do sertão paulista começou a partir do século $\mathrm{XVI}$, com as expedições dos bandeirantes. $O$ tempo de cada expedição variava de meses até anos, saindo normalmente de São Vicente ou São Paulo. Sob ordem do poder local, e com o intuito de achar ouro, os bandeirantes adentraram o estado através de caminhos já existentes feitos pelos indígenas. Ao longo de suas expedições montavam sítios a beira dos rios, não se fixando ali, pois seu intuito sobre o território paulista era de exploração, sem intenções de estabelecerem moradia. Posteriormente, por volta do século XIX, alguns desses sítios deixados para trás, foram palco da formação de pequenos povoados e posteriores cidades (CORRÊA et al, 1999). 


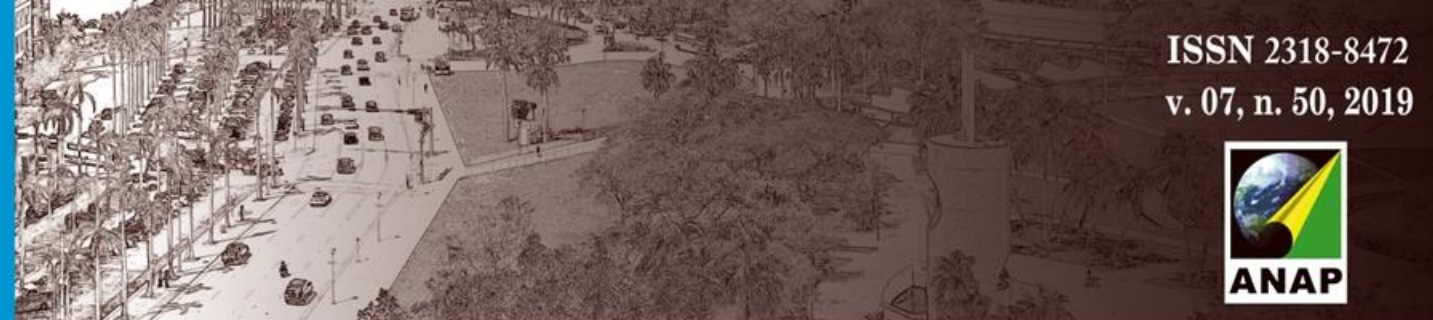

Revista Nacional de

Gerenciamento de Cidades

Os rios, nessas expedições, serviram como direção e caminho. Côrrea (2002) baseando-se em Capistrano de Abreu, Afonso de Taunay, Alfredo Ellis Júnior, Paulo Prado, Cassiano Ricardo e Sérgio Buarque de Holanda descreve a paisagem e a exploração do interior brasileiro, com enfoque no oeste paulista. $O$ autor relata que os rios eram parte de um relevo no qual os Bandeirantes utilizavam-se para desbravar o sertão brasileiro, incluindo o paulista. "Como caminhos, para a histografia, os rios precisaram a direção - o interior, o sertão - e a ação - o devassamento e a incorporação do sertão ao Brasil oficial. Definiram a marcha para o oeste, dos paulistas e da capital." (CÔRREA, 2002 p. 53). Apesar de utilizados como direção, os rios não tiverem uma relação importante com os bandeirantes como tiverem com as monções, logo em seguida.

Diferente dos bandeirantes que desbravaram o sertão paulista por terra em caminhos utilizados pelos índios e utilizavam o rio como direção, as monções usaram o próprio rio como forma de se locomoverem. O Tietê foi o principal rio paulista escolhido para cruzar o interior do estado.

As monções começaram a rarear a partir da segunda metade do século XVIII. Decai com elas a locomoção através da utilização dos rios, ficando essa restrita aos menores deslocamentos entre regiões. No século seguinte, mesmo com a criação da Comissão Geográfica e Geológica de São Paulo, que voltou a investigar e estudar os rios paulistas, o transporte hidroviário só será retomado quase cem anos depois com a criação da hidrovia Tietê-Paraná.

As monoculturas cafeeiras alteraram significativamente a paisagem do sertão paulista, desmatando terras e implantando ferrovias nos fundos de vale dos rios. Os fazendeiros adentraram o sertão paulista para implantação do café na proximidade dos cursos d'água, mas "os rios serviam apenas como pontos de referência para avançarem pelo interior da densa mata e, principalmente, para uma segura demarcação de suas propriedades." (CORRÊA et al., 2000 p. 71).

Assim como o café, a partir da segunda metade do século XIX, principalmente no final desse mesmo século, a indústria começa a desenvolver-se no Estado de São Paulo. No início, utilizavam energia hidráulica para seu funcionamento, o que acarretou seu estabelecimento ao longo dos rios, para utilizarem suas águas, gerando uma relação de dependência que desmatava as matas ciliares e trazia poluição. Foi através das indústrias que os rios começaram a ser vistos como mercadoria.

A partir do começo do século XX foram construídas barragens e novas usinas hidrelétricas, principalmente no rio Tietê, com o intuito de gerar energia para o novo estado industrial que estava se formando. A instalação de multinacionais foi um dos grandes motivos que impulsionou o desenvolvimento desse tipo de energia.

Durante a década de 40, muitos estudos foram realizados pensando na transformação dos rios Tietê e Paraná em vias navegáveis correntes, em hidrovia. Na década de 50, o DAEE (Departamento de Água e Energia Elétrica) e a CIBPU (Comissão Interestadual da Bacia do Paraná-Uruguai desenvolveram estudos para implantação de reservatórios em cascata, 



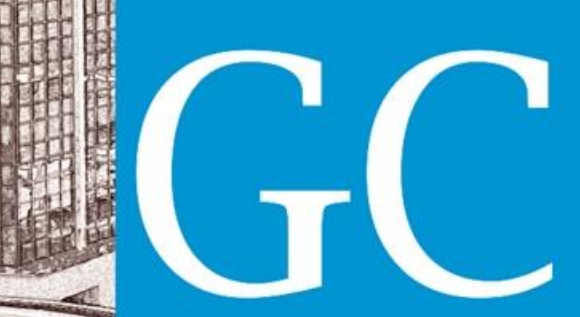

\section{Revista Nacional de}

Gerenciamento de Cidades

reservatórios cascatas. De 1990 a 1997, o volume de carga transportada passou de 1 milhão de tonelada para 6 milhões de toneladas por ano (FARRENBERG, 1998).

Com a construção da hidrelétrica às margens do rio Tietê, os usos e atividades foram alterados na região de Igaraçu e Barra Bonita. Algumas das olarias que ali haviam se instalado, inclusive em Igaraçu, tiveram que ser desativadas devido à inundação. Foi iniciada então uma discussão sobre como se realizaria a extração a partir daquele momento e como os proprietários das olarias, que dependiam da retirada da argila das margens do rio, seriam indenizados pela CHERP (Centrais Hidroelétricas do Rio Pardo) (MASSEI, 2007).

A inundação das bordas levou os ceramistas ao desenvolvimento de um mecanismo que permitiu extrair a argila submersa. Lançaram mão de um procedimento chamado ensecadeira. Com isso, eles escoam a água e extraem o barro que ficou submerso. Trata-se de um dique semelhante aos polders holandeses. Aproveitando-se o material que é inutilizado nas cerâmicas, terra e outros resíduos sólidos eles criam barreiras no rio em direção ao leito; concluem o fechamento desse trecho e colocam bombas de água para fazer a sucção. Assim, esvaziam por completo esse trecho do rio e promovem a extração com o uso da máquina retroescavadeira. Fazem-no, entretanto, de forma não-organizada e acabam por promover uma ação extremamente agressiva ao meio. (MASSEI, 2007, p. 6 e 7)

Dessas olarias poucas permanecem em funcionamento na cidade de Igaraçu e as outras foram abandonadas, observando que suas edificações estão em estado crítico, deteriorando-se com o tempo. É possível notar na figura 3 que as olarias não mais existem nas margens do rio.

Figura 3: Vista aérea das margens do Rio Tietê: Igaraçu do Tietê (esquerda) e Barra Bonita.

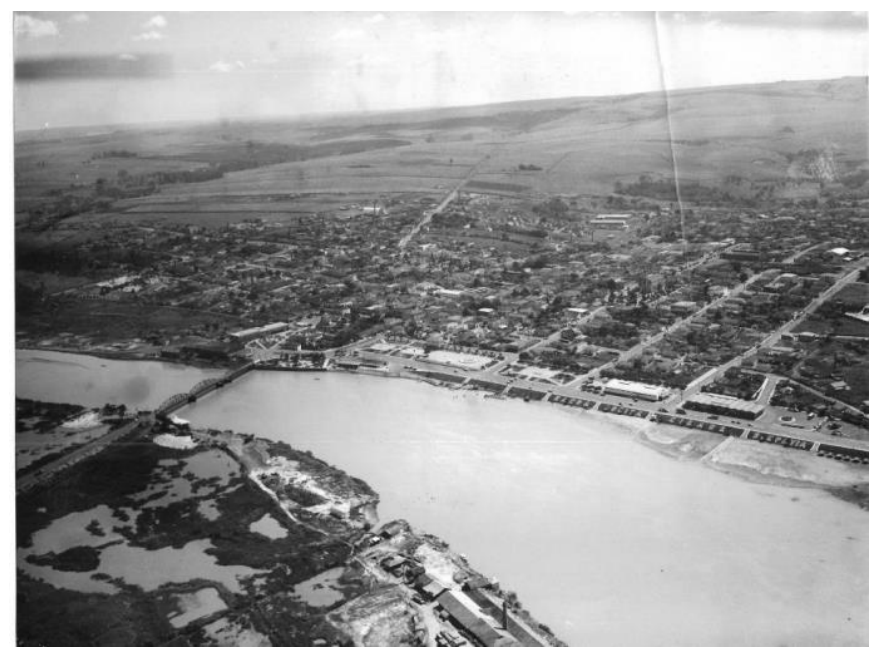

Fonte: Acervo Municipal de Barra Bonita. 


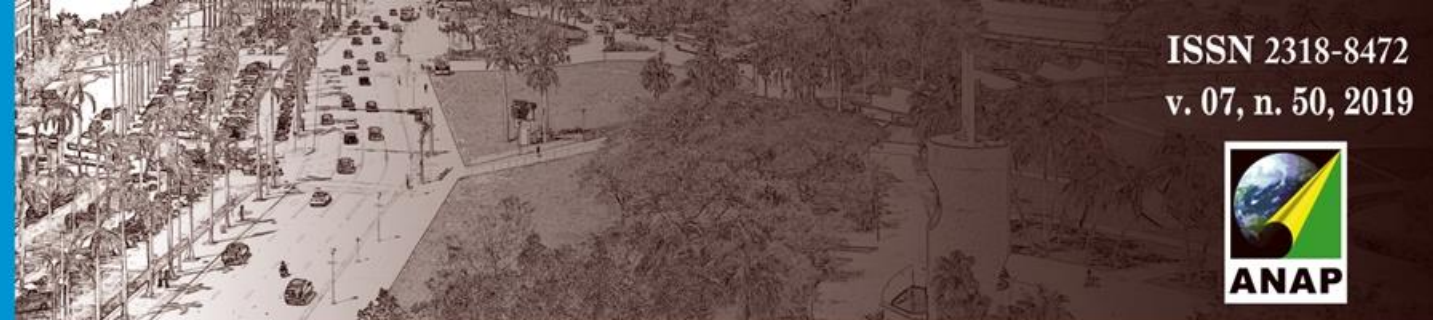

\section{Revista Nacional de}

Gerenciamento de Cidades

\subsection{Rio Tietê e as cidades de barra Bonita e Igaraçu do Tietê}

Durante o período das monções, era costume deixar algumas pessoas em lugares escolhidos com a incumbência de formarem pequenos roçados para o abastecimento das expedições na volta; esses locais eram chamados de "barra", e indicavam as margens que pudessem dar condições de ancorar suas embarcações (SAFFI et al.,1999). Barra Bonita seria, portanto, uma enseada com uma bela configuração natural, formando uma praia fluvial emoldurada por muitas espécies vegetal. O engenheiro Benjamim Franklin de Albuquerque Lima, chefe da Comissão de Exploração dos Rios Brasileiros, se referiu às barras como "margens bordadas de grande vegetação, onde abundam grossos madeiros e palmeiras de alto porte, sendo comum o cedro, a aroeira e a peroba" (LIMA, 1877, apud SAFFI et al., 1999, p.5). Assim, o Rio teve papel fundamental, não só na formação do município, como também na sua denominação.

O início dos investimentos turísticos em Barra Bonita aconteceu em 1964, durante o mandato do prefeito municipal Dr. Clodoaldo Antonangelo. No ano de 1966, o armazém da Cia. Paulista de Estrada de Ferro foi demolido e seu espaço concedido para um projeto de praça junto à orla da cidade, dando continuidade à área urbana já existente na época. (SOUZA, 2011). Tal projeto (Figura 4) consistia em um complexo multifuncional destinado ao lazer e ao esporte, que continha: jardins, plataforma para embarque e desembarque, estacionamento com 67 vagas pra carros e 23 para ônibus, anfiteatro, recinto para exposição de mamíferos e aves, aquário, lanchonete, praça, hotel beira-rio e piso da praça e dos passeios com mosaico português em quatro cores. "A área do projeto se localiza às margens do Rio Tietê e é praticamente inserida na malha urbana, estando bem próxima ao centro da cidade. Tem aproximadamente $78.000 \mathrm{~m}^{2}$ com declividades médias de 3 a 4\%, constituindo-se num suave terraço" (MELLO; ESCOBAR, 1982, p. 46). 


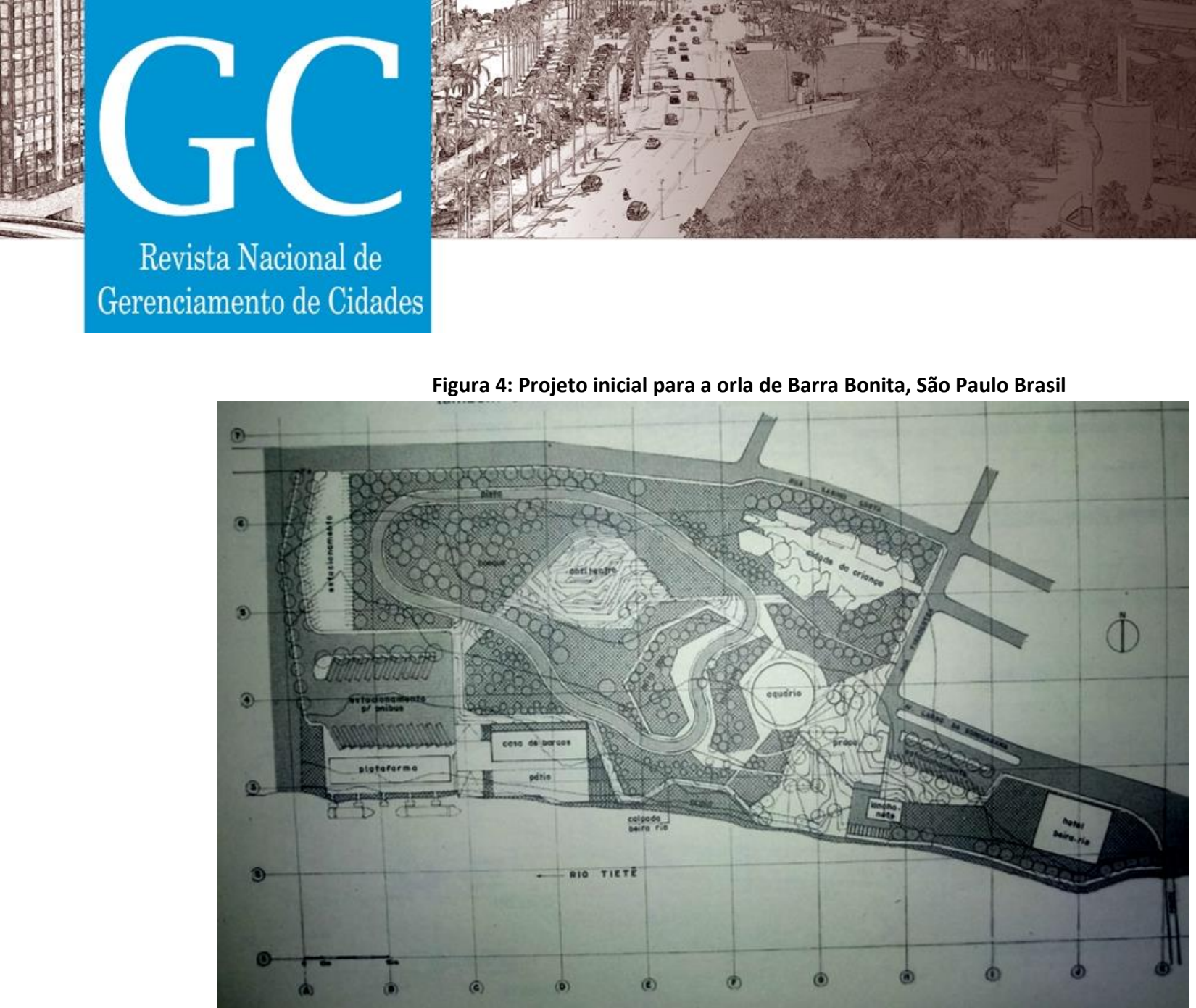

Fonte: MELLO; ESCOBAR, 1982

Alguns equipamentos constantes do projeto original foram descartados, como o aquário, o recinto para exposição de mamíferos e o anfiteatro. Outros, porém, foram mantidos, como o terminal de embarque e desembarque, as lanchonetes, o formato de algumas praças e principalmente o contato e a visão direta do Rio. "A preocupação original do projeto foi a de manter a margem do rio sempre acessível aos usuários, integrando todas as áreas de beira-rio, possibilitando ainda a constante visão do rio e suas margens" (MELLO; ESCOBAR, 1982 p, 47) Em 1967 foram inaugurados o Mercado Municipal e a Estação Rodoviária no terreno de um antigo barreiro de uma cerâmica que fora demolido (SOUZA, 2011). Nesse ano, o município recebeu uma grande quantidade de investimento no setor turístico, repercutindo seu potencial na Secretaria da Cultura, Esportes e Turismo do Estado, que, sob o decreto no 48.158/1967integrou Barra Bonita ao roteiro turístico do Estado de São Paulo.

O primeiro barco a navegar turisticamente pela cidade foi o chamado Crepúsculo Romântico, impulsionando o turismo de navegação que se consolidou em novembro de 1973, com a abertura da eclusa Dr. José Bonifácio de Andrada e Silva Jardim pelo Ministro dos Transportes, na época, Mário Andrezza; essa eclusa com 142m de comprimento, $12 \mathrm{~m}$ de largura e capacidade de transposição de até 2.000 toneladas, tornou-se a primeira da América do Sul a ser explorada turisticamente (MUCARE; BRESSAN, 1986). Nesse mesmo ano, foi inaugurada a Minicidade, um parque para as crianças contendo a Igreja Matriz e um castelo em miniaturas e os brinquedos convencionais (SOUZA, 2011). Em 1979 foi transformada em Estância Turística, sob a Lei Estadual no 2109, pelo governador Paulo Salim Maluf. 


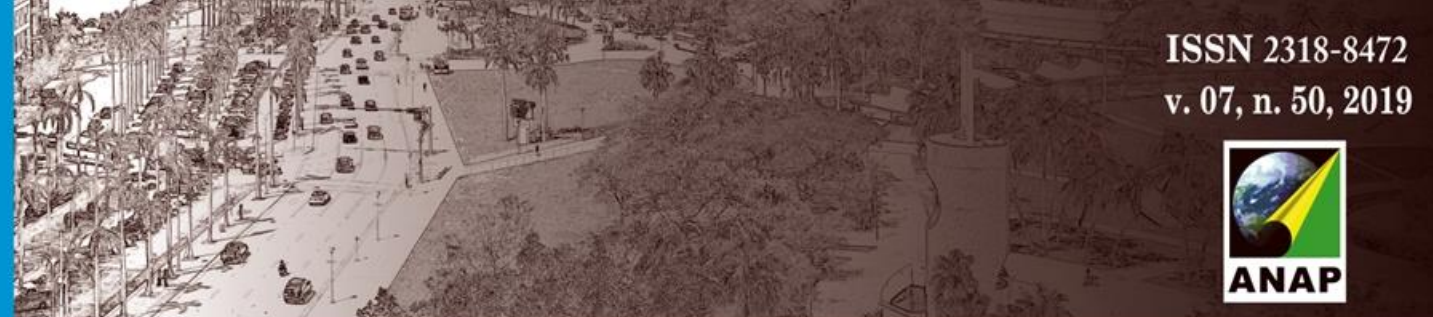

\section{Revista Nacional de}

Gerenciamento de Cidades

Embora seja reconhecida como cidade turística, o Turismo representa uma parte incipiente da economia de Barra Bonita, sendo sua principal fonte de renda a produção de açúcar e álcool. Em relação à vegetação, o município está inserido em porções do Cerrado e Mata Atlântica, porém a parte urbana se restringe exclusivamente à área de Cerrado (ARROBA, 2018). Contudo, a vegetação nativa é quase inexistente, sendo a paisagem dominada pela monocultura de cana. Segundo representante da Companhia Fluvial Tietê-Paraná, a mata ciliar é quase ausente ao longo do rio (PENTEADO et.al, 2017).

Considerando o território como um todo, a agricultura mostra-se como a principal modeladora da paisagem, sendo esta quase que exclusivamente composta por cana-de-açúcar. Em relação às demais classes, percebe-se que a representatividade delas é muito semelhante. Isso indica também que a água é um importante elemento na paisagem, pois os rios e o urbano têm representatividade muito similar na paisagem (6,9\% e 7,4\%, respectivamente). Se focar apenas nos limites, é possível perceber isso mais claramente, pois as águas banham a área urbana. Outro ponto a observar é que a maioria dos rios, seja na parte urbana, seja na parte rural, não contam com os 30m de APP (Áreas de Proteção Permanente) de mata ciliar, estabelecidos pelo Art. 40 do Novo Código Florestal (BRASIL, 2012).

Na Figura 5 está presente um zoom na área urbana, onde estão destacados os cursos d'águas e fragmentos florestais, evidenciando a importância desses elementos na paisagem, se comparado exclusivamente com o urbano e mostrando as delimitações do que deveriam ser as Áreas de Preservação Permanente - APPs.

Na outra margem do rio, Igaraçu do Tietê começou a ser cercada por grandes monoculturas açucareiras que geram uma grande quantidade de cana, levada principalmente às indústrias de Barra Bonita para a produção de açúcar. No início da década de 1970 o tráfego pesado de açúcar precisava ser desviado da ponte Campos Salles, única ligação entre Igaraçu do Tietê e Barra Bonita, para garantir sua preservação. Por esse motivo, em 19 de setembro de 1970 é inaugurada uma segunda ponte de ligação entre as duas cidades que se conectava com a rodovia SP-255. A ponte ficou conhecida como "Ponte do Açúcar". (SAFFI, 1991). 


\section{Revista Nacional de}

Gerenciamento de Cidades

Figura 5: As nascentes, rios, córregos e fragmentos florestais estão destacados na parte urbana do município de Barra Bonita, São Paulo, Brasil. Ao lado, imagens das margens do rio nos arredores do município.
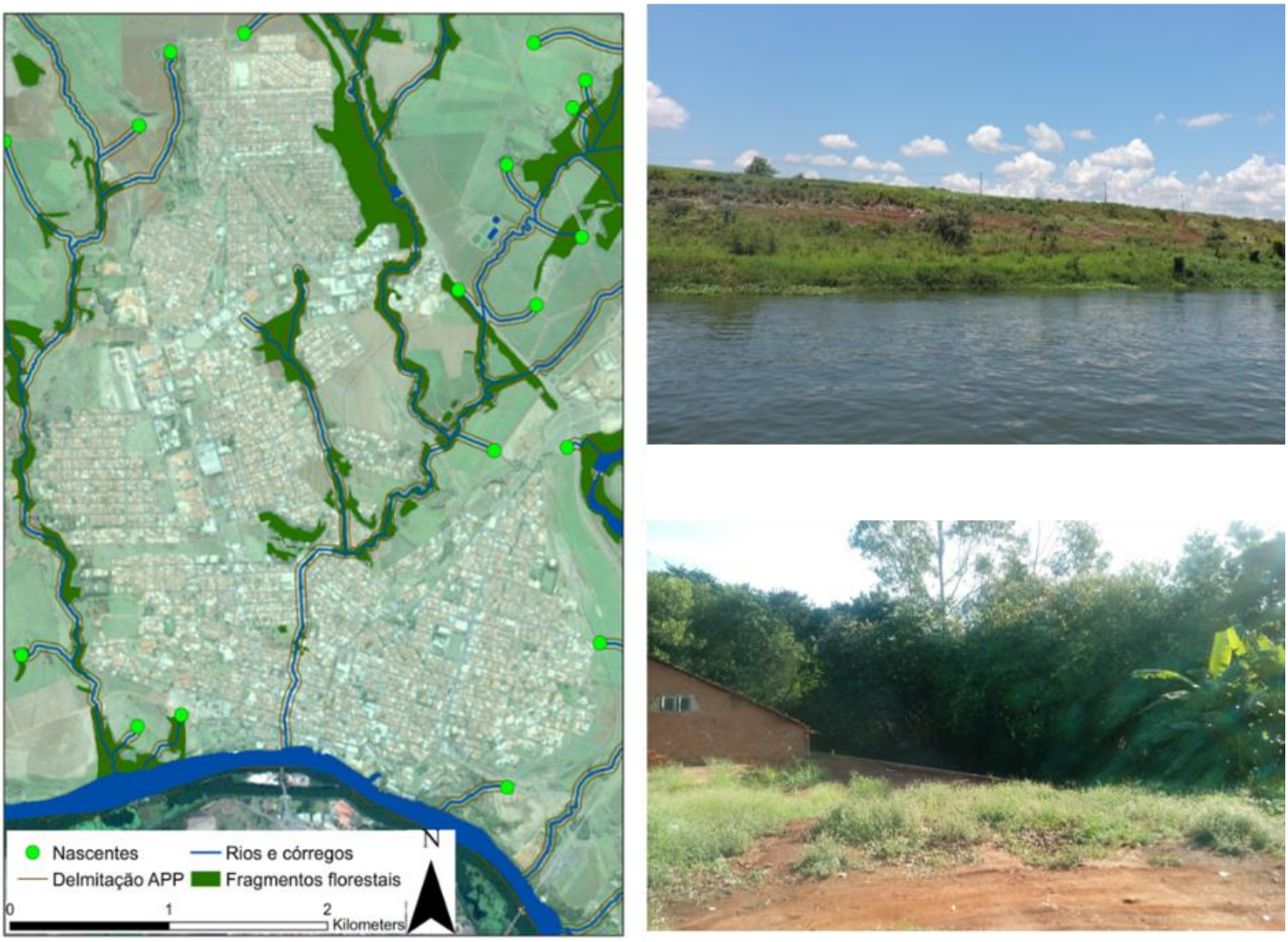

Fonte: Mapa e fotos de autoria própria

Segundo entrevista com o Secretário de Turismo de Igaraçu do Tietê (em fevereiro de 2017), começou a se estabelecer na cidade a partir de 1960, próximo à barragem, uma praia fluvial, acompanhada de novas construções, para gerar infraestrutura (RIPKE, 2017). O município começa então a receber os turistas interessados no lazer fluvial. Apesar do início do estabelecimento da prainha, as margens do rio em Igaraçu na década de 1970 ainda possuíam uma paisagem que se caracterizava pela exploração das águas, com a presença de áreas alagadas e vegetação quase inexistente. Em 1994, Igaraçu do Tietê tornou-se uma estância turística. A cidade possui pontos de atrações como a prainha, o parque "Igaraçu Park" às margens do rio Tietê, as pontes Campos Salles e Ponte do Açúcar, além de hotéis destinados a receber turistas. A cidade organiza o carnaval que também atrai grande quantidade de pessoas de outras localidades nos dias de celebração.

Diferente de Barra Bonita, localizada na margem oposta, que possui uma maior infraestrutura para turistas e maiores investimentos, Igaraçu ainda está se desenvolvendo no setor, investindo em melhorias nos equipamentos já existentes na prainha (Figura 6) e no parque municipal, e criando estratégias para atração de maior quantidade de turistas, essencial para aumentar a arrecadação do município. 


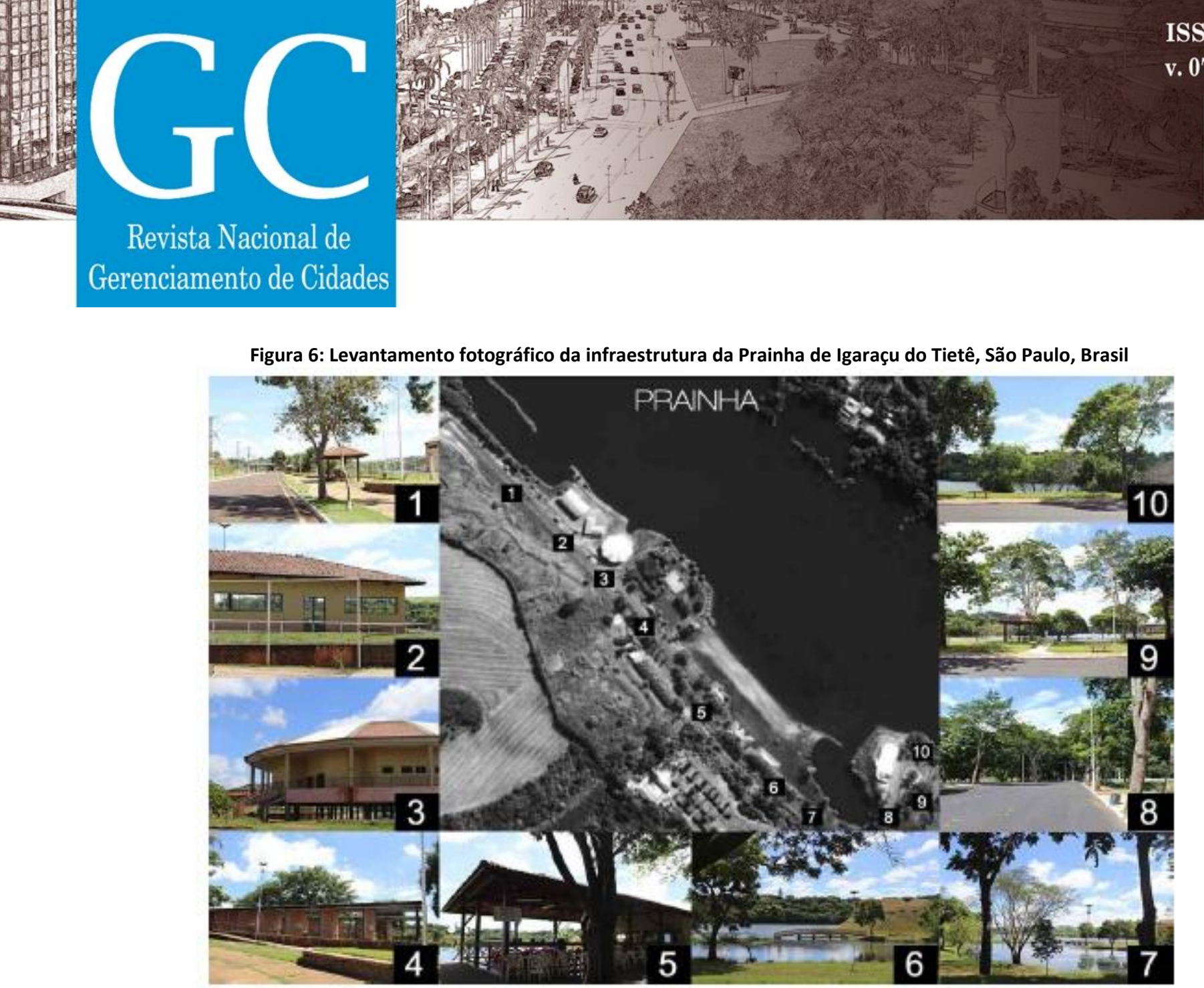

Fonte: Ripke, 2017

Igaraçu do Tietê possui sua relação com o rio vinculada estritamente à zona urbana. A cidade teve seu desenvolvimento ao longo dos anos, muito atrelado às águas. $O$ rio Tietê foi utilizado para a travessia até Barra Bonita, depois pelas olarias para fabricação de tijolos e telhas cerâmicas, para o fornecimento de energia gerada através da construção da barragem, para o transporte fluvial, para a extração de matéria prima como o barro e a areia, e para o turismo. 0 trecho ao longo do rio Tietê possui três tipos de uso e vínculo com a população. No primeiro trecho encontra-se a prainha, localizada a oeste do município, próximo à barragem, com um uso intenso e uma paisagem atrativa. O segundo, entre a prainha e o parque municipal, é afastado da população pela vegetação e pela falta de atratividade. Por último, partindo do parque até à cidade de Macatuba, o terceiro trecho caracteriza-se pelo intenso uso próximo ao parque municipal, mas este uso vai decrescendo a medida que o rio se distancia da malha urbana.

Ambas as cidades são abastecidas pela hidrelétrica de Barra Bonita. Inaugurada em 1973 para suprir a demanda por energia elétrica, a hidrelétrica promoveu intensas transformações na economia regional. O complexo hidroenergético foi construído e administrado integralmente pelo Estado até a década de 90, quando em 1996, passou a ser concessão na multinacional AESTietê (PENTEADO et al. 2017). A eclusa tem uma bacia hidrográfica de $32.330 \mathrm{Km}^{2}$, potencial máxima de $140.760 \mathrm{Kw}$ e potencial normal de $112.400 \mathrm{Kw}$ (PETBB, 2013). Por ter sido construída antes da Resolução no 1 do CONAMA (Conselho Nacional de Meio Ambiente) de 1986, a barragem e eclusas foram construídas sem os Estudos e Relatórios de Impactos Ambientais. 


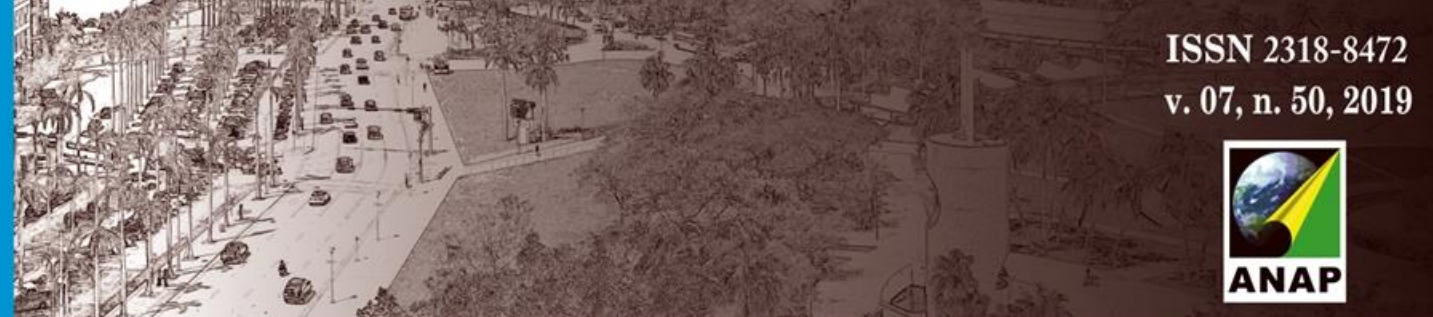

\section{Revista Nacional de}

Gerenciamento de Cidades

Portanto não houve estudos da biodiversidade local antes de sua construção e nem a previsão e medidas de mitigação de impactos, obrigatórios atualmente. Desse modo, não é possível saber com exatidão o que se perdeu do ponto de vista arqueológico, ambiental e cultural, uma vez que nessa época não havia leis que se preocupavam com essas questões.

\subsection{Percepção do Rio pela população de Igaraçu e Barra Bonita}

Ao todo foram aplicados 270 questionários aos habitantes de Barra Bonita e Igaraçu. Como resultado, vimos que $94,8 \%$ dos usuários consideram o Rio Tietê como uma opção interessante de lazer, 99,6\% o consideram como uma parte importante da cidade e $87,8 \%$ dos usuários declararam saber que o Rio teve importância para a história da fundação do município. Contudo, apenas 59,3\% (160 pessoas) dos usuários declararam ter algum vínculo afetivo com o rio. Entre eles, 156 explicitaram os seus motivos que foram agrupados 8 categorias principais: infância, contemplação/vínculo espiritual, sentimentos bons, pertencimento/história da cidade, trabalho, turismo, barco e pesca. Em primeiro lugar, a justificativa mais levantada para esse vínculo foi a memória da infância. Nesse sentido, 52 entrevistados mencionaram que quando crianças passaram bons momentos em sua orla ou navegando no rio. Muitos ainda contaram que aprenderam a nadar no rio e têm uma memória de vivência de adolescência e infância, cujo cenário se passa no Rio Tietê. Em segundo lugar, o vínculo foi justificado por despertar sensações boas como alegria, amor, paz, felicidade e amor pela natureza. Em terceiro lugar, o vínculo está atrelado ao trabalho, onde 20 pessoas justificaram seu afeto pelo rio porque trabalham nele diretamente ou porque a renda está vinculada a alguma atividade relacionada ao seu turismo. Em quarto lugar, 17 pessoas justificaram seus vínculos devido à contemplação e/ou aspectos espirituais como um local para meditação ou para recarregar as energias. 


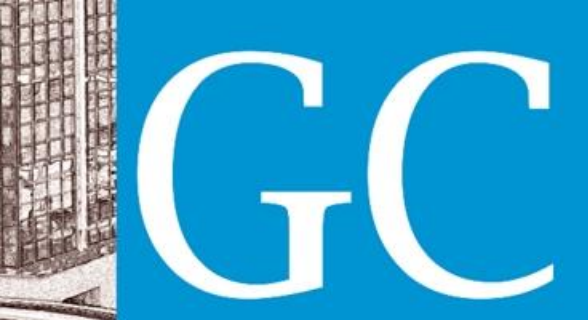

Revista Nacional de

Gerenciamento de Cidades

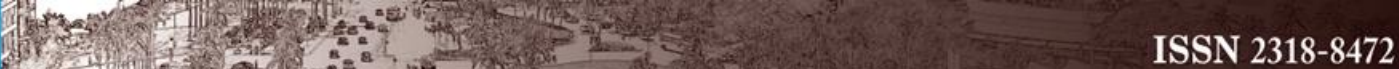

v. 07 , n. 50, 2019

Figura 7: Nuvem de palavras associadas ao Rio Tietê em Barra Bonita.

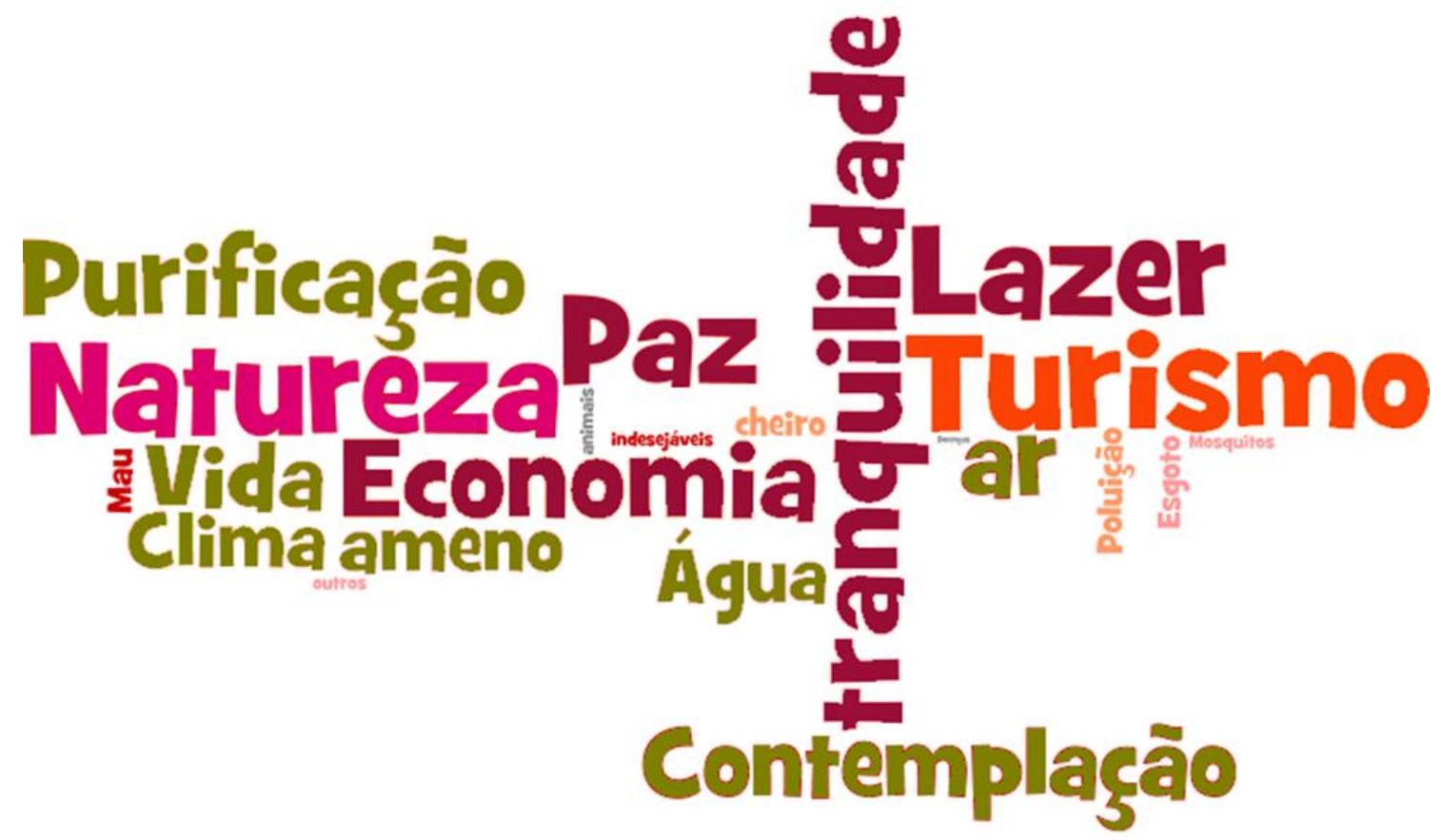

Fonte: Figura elaborada pela autora com a ferramenta Wordle

Além disso, nos questionários aplicados com a população foram apresentadas 15 palavras, sendo 5 representando aspectos negativos (esgoto, poluição, odor, mosquitos, doenças), 5 aspectos positivos (paz e tranquilidade, contemplação, turismo, economia, lazer) e 5 palavras relacionadas a aspectos naturais do rio (água, clima-ameno, vida, natureza, purificação do ar). Depois foi solicitado para que cada entrevistado escolhesse entre as palavras disponíveis, aquelas que se relacionassem com a influência do rio na cidade e/ou em suas vidas pessoais. As cinco palavras mais assinaladas pela população foram: 1ㅇ Turismo (240), 2ㅇ Natureza (222), 3은 Lazer (217), 4 Paz e Tranquilidade (200) e 5o Economia (184). Esse resultado mostrou que apesar do Rio ser um local de despejo de esgoto, a maioria das pessoas enxerga mais aspectos positivos como influência do rio. Para esse resultado, usamos o programa Wordle e obtivemos a nuvem presente na Figura 7, onde as palavras em letras maiores e com cores diferentes representam as mais mencionadas. As verdes representam as mencionadas com frequência médio-alta e as menores e coloridas são as pouquíssimo mencionadas.

A partir do resultado dessas entrevistas, foi possível perceber que a população de Igaraçu e Barra Bonita possui uma relação muito forte com o rio no contexto da paisagem urbana. Porém, embora a população considere o rio como parte essencial da cidade e tenha um vínculo afetivo muito forte, há muito ainda a ser aperfeiçoado e explorado, principalmente considerando o contexto socioambiental. A expansão do tratamento de esgoto de $20 \%$ para $100 \%$ é uma medida emergencial que está em fase de andamento e construção. Com a estação de tratamento em funcionamento, muitos outros aspectos poderão ser aperfeiçoados como o uso do rio para 


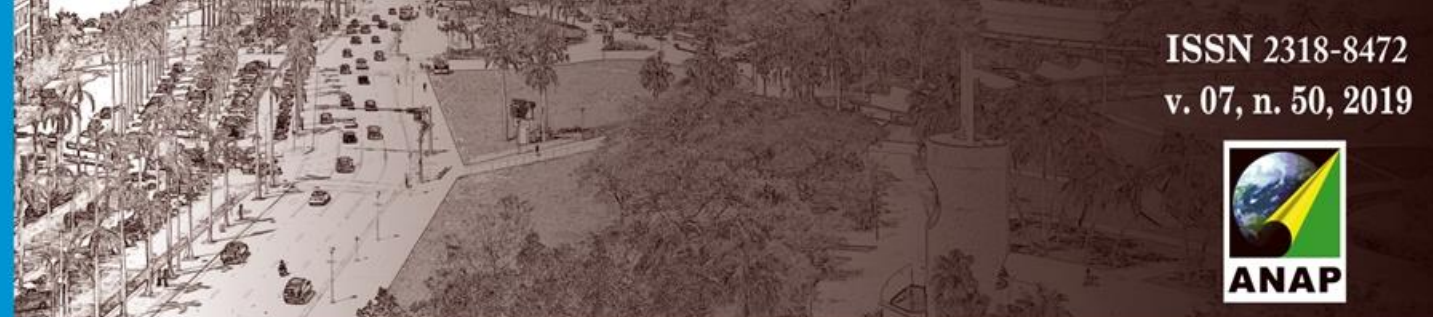

Revista Nacional de

Gerenciamento de Cidades

nadar, além dos esportes aquáticos. Considerando o potencial turístico da cidade, com a inclusão desses novos usos será possível explorar novas formas de turismo e consequentemente impulsionar a economia da cidade. Do mesmo modo, é necessária a criação de infraestrutura compatível ao turismo, como a implantação de hotéis, campings, bares e restaurantes que atraiam novos visitantes.

Em relação às áreas de APP (Áreas de Proteção Permanente), sua restauração e reflorestamento com espécies nativas são de fundamental importância para evitar os processos de erosão e assoreamento e também para filtrar poluentes e, consequentemente, melhorar a qualidade das águas (PENTEADO, et al. 2017).Além disso, tais áreas poderiam ser pensadas como infraestrutura verde, conciliando espaços de contato social com a natureza, mas também a criação de corredores ecológicos que conectem fragmentos e elementos na paisagem. Se faz necessário também que o município invista em saneamento básico, tratamento de $100 \%$ de esgoto, cumprimento das leis ambientais e incentivo ao uso de espaços livres. Tais medidas trariam um novo aspecto e ajudariam a melhorar a posição do município em relação ao Programa Município Verde Azul, o que poderia propiciar futuramente, o recebimento de bônus e novas verbas do Programa, destinadas à melhoria da paisagem. Além disso, é possível aprimorar sua relação da interação da população com o Rio Tietê, trazendo opções de contato com a água para a população urbana, seja por meio das fontes, seja pela criação futura de decks e piscinas naturais que atraiam as pessoas a se aproximarem das águas.

\section{CONSIDERAÇÕES FINAIS}

O Rio Tietê no oeste do Estado é uma fonte econômica importante para as cidades que se estabeleceram perto de suas margens, seja pela produção e fornecimento de energia, transporte de cargas ou pelo turismo. A partir da pesquisa realizada foi possível obter um panorama amplo sobre Barra Bonita e Igaraçu do Tietê, analisando a relação com o rio. O Rio Tietê foi fundamental na formação das cidades, estando inserido do ponto de vista da paisagem como processo histórico e como representação cultural, já que o Rio foi o modelador essencial para a formação da Hidrovia Tietê-Paraná e a Hidrelétrica de Barra Bonita. Do ponto de vista estético, o Rio tem fundamental importância, pois é um atrativo turístico para navegação e contemplação.

Em decorrência dos acontecimentos históricos e do modelo de desenvolvimento, atualmente, no século XXI, a paisagem do Rio Tietê se modificou profundamente. Se antes a paisagem do Tietê estava presente nos imaginários dos exploradores, naturalistas e viajantes das monções paulistas como um rio misterioso que proporcionava viagens repletas de aventuras, perigosas cachoeiras e animais selvagens, hoje trata-se de um rio com leito semi-parado, completamente domesticado pelo homem. Sua paisagem, alterada quase que integralmente, apenas mantémse preservada em sua nascente, dentro dos limites dos Parques Nascentes do Rio Tietê e Parque Ecológico do Rio Tietê. Fora desses limites, suas águas foram poluídas, suas margens alargadas, suas curvas retificadas e sua vegetação transformada em monoculturas de produção intensiva. 

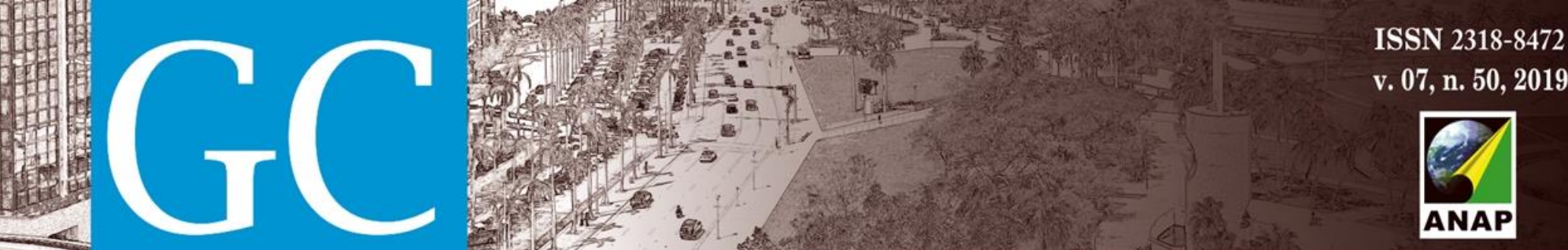

\section{Revista Nacional de}

Gerenciamento de Cidades

SOUZA, H. Novo atrativo turístico para a orla de Barra Bonita-SP: Memorial do Rio Tietê. Trabalho Final de Graduação em Arquitetura e Urbanismo, FAAC - Faculdade de Arquitetura, Artes e Comunicação, UNESP (Universidade Estadual Paulista), 2011

SOUZA, J.S.; MAKINO, M. Diários de Navegação - Teotônio José Juzarte. Comemoração 500 anos de Brasil. São Paulo: Edusp, 2000

SUKOPP, H. Chapter Urban Ecology - Scientific and Practical Aspects. In: BREUSTE, H; FELDMANN, O; UHLMANN, J. Book Urban Ecology pp. 3 - 16. Springer-Verlag Berlin Heidelberg 1998.

TRATA BRASIL. Ranking do Saneamento. São Paulo, 2016.

XU, H.; LV, D.\& FAN, Y. A Pragmatic Framework for Urban River System Plan in Plain River Network Area of China. 2012International Conference on Modern Hydraulic Engineering. Procedia Engineering 28, 2012, p.494-500 